Check for updates

Cite this: RSC Adv., 2017, 7, 53379

Received 7th September 2017

Accepted 1st November 2017

DOI: 10.1039/c7ra09972j

rsc.li/rsc-advances

\title{
Multicolorful ratiometric-fluorescent test paper for determination of fluoride ions in environmental water $\dagger$
}

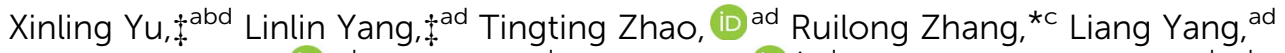 \\ Changlong Jiang, (D) ad Jun Zhao, ad Bianhua Liu (D) *ad and Zhongping Zhang abcd
}

\begin{abstract}
Here, a ratiometric fluorescent test paper for the visual and on-site determination of environmental fluoride ions was fabricated by inkjet-printing of the as-prepared "ink" onto a filter paper. The "ink" was prepared by mixing the fluoride-sensitive organic probe (C-TIPS) with red CdTe quantum dots (QDS) in an optimal proportion. The designed fluorescent fluoride probe shows a turn-on effect in the presence of fluoride ions. With the aid of thee red fluorescence of CdTe QDs, the test paper exhibited a distinguishable fluorescence color change from red to purple to blue under a UV lamp. The as-prepared ratiometricfluorescent test paper displayed a superior sensitivity and visual effectiveness to quantify fluoride ions, with a detection limit of $0.285 \mu \mathrm{M}$ which is lower than the World Health Organization (WHO) defined limit $(79 \mu \mathrm{M})$. Moreover, the test paper is highly applicable for the detection of fluoride ions in natural waters in a very simple, cost efficient and on-site way.
\end{abstract}

\section{Introduction}

Fluoride ions $\left(\mathrm{F}^{-}\right)$, as one of the essential micronutrients to humans and animals, provide strength to teeth and bones to prevent dental cavities and osteofluorosis, and thus can be widely found in toothpaste and used to cure bone diseases. ${ }^{\mathbf{1 , 2}}$ For dental health, $\mathrm{F}^{-}$is added into drinking water in many countries and the maximum limit of $\mathrm{F}^{-}$in drinking water is $79 \mu \mathrm{M}$ (1.5 ppm), as recommended by the WHO. ${ }^{3}$ Meanwhile, it has been proved that excessive $\mathrm{F}^{-}$is very harmful to our health and leads to numerous diseases, such as dental and skeletal fluorosis, kidney and gastric abnormalities, and even death., Recent estimations show that about 200 million people, among 25 nations all over the world, are still threatened by excessive $\mathrm{F}^{-}$ from underground water or polluted water. ${ }^{6}$ Therefore, it is an urgent demand for human health to effectively quantify $\mathrm{F}^{-}$in drinking water. Traditional methods, including ${ }^{19} \mathrm{~F}$ NMR spectroscopy, ${ }^{7}$ ion-selective electrodes ${ }^{\mathbf{8}}$ and ion chromatography, ${ }^{\mathbf{9}}$ inevitably require relatively cumbersome equipment,

${ }^{a}$ Institute of Intelligent Machines, Chinese Academy of Sciences, Hefei, Anhui 230031, China.E-mail: bhliu@iim.ac.cn

${ }^{b}$ Department of Chemistry, University of Science and Technology of China, Hefei, Anhui 230026, China

${ }^{c}$ School of Chemistry and Chemical Engineering, Anhui University, Hefei, 230601, China.E-mail: zrl@ahu.edu.cn

${ }^{d}$ State Key Laboratory of Transducer Technology, Chinese Academy of Sciences, Hefei, Anhui 230031, China

$\dagger$ Electronic supplementary information (ESI) available. See DOI: 10.1039/c7ra09972j

\$ These authors contributed equally to this work. complicated pre-treatments of samples, and professional operators, which hinder their application in the convenient and effective detection of $\mathrm{F}^{-}$.

Compared to these conventional approaches, fluorescent and chromogenic probes have been developed for the detection of $\mathrm{F}^{-}$, owing to their advantages of excellent sensitivity/selectivity and simple operation. ${ }^{\mathbf{1 0 - 1 3}}$ The reported strategies have mainly focused on the following three approaches, $\mathrm{F}^{-}$-induced cleavages of chemical bond ( $\mathrm{Si}-\mathrm{O} / \mathrm{Si}-\mathrm{C}$ and $\mathrm{B}-\mathrm{O}$ bonds), and the formation of hydrogen bonds with $\mathrm{F}^{-}$and $\mathrm{F}^{-}$-substituted metal complexes. ${ }^{14-18}$ Among them, the $\mathrm{F}^{-}$-triggered selective cleavages of the $\mathrm{Si}-\mathrm{O}$ bond approach exhibits a higher specificity and sensitivity. ${ }^{19-30}$ However, most of the reported studies depended on sophisticated fluorescent instruments, which pose difficulties to meet the requirements of on-site assays.

Fluorescent test paper, ${ }^{31,32}$ like $\mathrm{pH}$ test paper, is one of the most convenient methods for on-site assays, and hence many efforts have been devoted to developing new fluorescent paper sensors. Organic dyes, quantum dots (QDs), carbon dots, and up-conversion nanomaterials have been applied to fluorescent test paper for the visual detection of various target analytes, such as explosives, heavy metal ions, and biological molecules. ${ }^{33-38}$ In the present work, a ratiometric fluorescent "ink" for the selective detection of $\mathrm{F}^{-}$was prepared by mixing a nonfluorescent $\mathrm{F}^{-}$probe and red QDs in an optimal proportion, in which the fluorescence of the probe can be lighted up by $\mathrm{F}^{-}$ while the red fluorescence of the QDs remains constant. The two independent fluorescence emission peaks used in ratiometric fluorescent sensing can effectively eliminate background interferences and improve the sensitivity of the sensor by self- 
calibration. ${ }^{39}$ The "ink" displayed dramatically recognizable fluorescence color responses to $\mathrm{F}^{-}$, therefore achieving effective visualization assays of $\mathrm{F}^{-}$. On the basis of the above results, we could further prepare the test paper sensor for the visual detection of $\mathrm{F}^{-}$by inkjet-printing the "ink" onto a piece of filter paper. Compared to "turn on/off" fluorescent systems, the asprepared ratiometric fluorescent test paper could display a superior selectivity and better visual effectiveness to quantify $\mathrm{F}^{-}$because the naked eye is more sensitive to the variations of color than those of brightness. ${ }^{40}$ Moreover, the ratiometric fluorescent test paper could be further applied to the visual assays of $\mathrm{F}^{-}$in environmental waters.

\section{Experimental}

\section{Reagents and materials}

All the chemicals used were analytical grade. 7-Hydroxycoumarin, triisopropylsilyl chloride (TIPSCl), NaH, 3-mercaptopropionic acid (MPA), Te powder, $\mathrm{NaBH}_{4}$, and $\mathrm{CdCl}_{2} \cdot 2.5 \mathrm{H}_{2} \mathrm{O}$ were purchased from Sigma-Aldrich. $\mathrm{NaOH}, \mathrm{H}_{2} \mathrm{SO}_{4}(98 \%)$, tetrahydrofuran (THF), methanol, and ethanol (EtOH) were supplied by Sinopharm Chemical Reagent Company, Ltd. (Shanghai, China). Dry THF was obtained by distillation after being refluxed with sodium metal (benzophenone as indicator). Ultrapure water $(\geq 18.2 \mathrm{M} \Omega$ ) was prepared by a Millipore water purification system. The solutions of anions were prepared from $\mathrm{NaF}, \mathrm{NaCl}, \mathrm{NaBr}, \mathrm{NaI}, \mathrm{NaClO}_{4}, \mathrm{NaNO}_{3}, \mathrm{NaAc}, \mathrm{NaH}_{2} \mathrm{PO}_{4}$, $\mathrm{NaHCO}_{3}, \mathrm{NaNO}_{2}$, and NaSCN. They were dissolved in sterilized ultrapure water. Caution: The $\mathrm{NaH}$ is a fire hazard, so it should be used carefully and handled only in small quantities.

\section{Collection and storage of human urine}

Human urine samples, collected from healthy volunteers with informed consent, were stored in a $4{ }^{\circ} \mathrm{C}$ refrigerator for further use. All experiments were performed in compliance with the Ethical Committee Approval of China and approved by the ethics committee at the Institute of Intelligent Machines (Chinese Academy of Sciences).

\section{Instruments}

${ }^{1} \mathrm{H}$ and ${ }^{13} \mathrm{C}$ NMR spectra were performed on a Bruker Ultrashield spectrometer using TMS as the internal standard. The peak multiplicities are shown by the abbreviations: s, singlet; d, doublet; m, multiplet. High-resolution mass spectra (HR-MS) were measured using an Agilent Q-TOF 6540 mass spectrometer. Fluorescence spectra were measured by a Cary Eclipse fluorescence spectrophotometer. Fluorescent photos were taken under an AGL-9406 UV lamp (365 nm excitation) with a Canon 600D digital camera. HPLC spectra were performed using a C18 column under methanol/water $(7: 3, \mathrm{v} / \mathrm{v})$ mobile phase conditions and the intensities were detected by a $375 \mathrm{~nm}$ UV detector.

\section{Synthesis of 7-((triisopropylsilyl) oxy)-2H-chromen-2-one (C- TIPS)}

According to the reported method, ${ }^{\mathbf{4 1}}$ the fluorescent probe CTIPS was synthesized as follows: 7-hydroxycoumarin $(162 \mathrm{mg}$,
$1 \mathrm{mmol}$ ) was first dissolved in $30 \mathrm{~mL}$ of dry $\mathrm{THF}$, then $\mathrm{NaH}$ powder with $70 \%$ purity $(68.6 \mathrm{mg}, 2 \mathrm{mmol})$ was added into the solution. After stirring for $30 \mathrm{~min}$ at $0{ }^{\circ} \mathrm{C}$ under a nitrogen atmosphere, TIPSCl (390 $\mathrm{mg}, 2 \mathrm{mmol}$ ) was dropped into the mixture and continuously stirred at room temperature overnight. After the reaction was completed (monitored by TLC), $1 \mathrm{~mL}$ of EtOH was added into the reaction solution to quench the residual $\mathrm{NaH}$, and the generated precipitate was filtered off. Then the filtrate was concentrated under vacuum. Finally, the residue was purified through a silica gel column eluted with petroleum ether/ethyl acetate $(50: 1, \mathrm{v} / \mathrm{v})$ to afford C-TIPS as a colorless solid with a yield of $89.7 \%$. ${ }^{1} \mathrm{H}$ NMR $(400 \mathrm{MHz}$, $\left.\mathrm{CDCl}_{3}\right) \delta 7.63(\mathrm{~d}, J=9.5 \mathrm{~Hz}, 1 \mathrm{H}), 7.37-7.29(\mathrm{~m}, 1 \mathrm{H}), 7.26(\mathrm{~s}, 1 \mathrm{H})$, 6.87-6.74 (m, 2H), $6.25(\mathrm{~d}, J=9.5 \mathrm{~Hz}, 1 \mathrm{H}), 1.35-1.22(\mathrm{~m}, 3 \mathrm{H})$, 1.16-1.06 (m, 18H); $\left.{ }^{13} \mathrm{C} \mathrm{NMR} \mathrm{(100} \mathrm{MHz,} \mathrm{CDCl}_{3}\right) \delta 161.31,159.89$, 155.76, 143.47, 117.47, 113.29, 113.07, 107.62, 79.10-74.66 (m), 17.92, 12.74; HR-MS ( $m / z$, ESI) calculated for $\mathrm{C}_{18} \mathrm{H}_{27} \mathrm{O}_{3} \mathrm{SiNa} m / z$ $=341.1549[\mathrm{M}+\mathrm{Na}]$. Found $m / z=341.1540$.

\section{Synthesis of CdTe QDs}

CdTe QDs were prepared based on a reported method. ${ }^{42}$ Te powder $(128 \mathrm{mg})$ and $\mathrm{NaBH}_{4}(200 \mathrm{mg})$ were added into $5 \mathrm{~mL}$ of ultrapure water at $0{ }^{\circ} \mathrm{C}$ with $\mathrm{N}_{2}$ protection, and then the mixture was stirred for $6 \mathrm{~h}$ to obtain NaHTe solution. At the same time, $\mathrm{CdCl}_{2} \cdot 2.5 \mathrm{H}_{2} \mathrm{O}(460 \mathrm{mg})$ and MPA $(420 \mu \mathrm{L})$ were added into $200 \mathrm{~mL}$ of ultrapure water, and the $\mathrm{pH}$ value was adjusted to 11 with diluted $\mathrm{NaOH}$ aqueous solution, and then $\mathrm{N}_{2}$ was bubbled into the solution for half an hour to remove dissolved $\mathrm{O}_{2}$. Then, $10 \mathrm{~mL}$ of $0.5 \mathrm{M} \mathrm{H}_{2} \mathrm{SO}_{4}$ was injected into the prepared NaHTe solution above, and the $\mathrm{H}_{2}$ Te gas produced was bubbled into the mixture of $\mathrm{CdCl}_{2}$ and MPA under an inert $\mathrm{N}_{2}$ atmosphere. When the color of the mixture changed to orange, the gas bubbling was halted. After continuously refluxing for another 2 days, CdTe QDs with a red emission at $630 \mathrm{~nm}$ were prepared. Finally, the QDs were purified by precipitation with acetone and dispersed in the mixture solution of ethanol/water $(7: 3, \mathrm{v} / \mathrm{v})$ for further use.

\section{Preparation of test paper}

The preparation method was according to the reported reference. ${ }^{34}$ Firstly, a common ink box of a commercial inkjet printer was washed with ultrapure water until the ink was completely cleared away, and dried thoroughly. Secondly, the as-prepared ratiometric fluorescent solution was injected into the vacant cartridge as ink. Then, commercially available filter paper was stuck onto a piece of A4 paper. Finally, a square pattern of $4 \times 4$ $\mathrm{cm}^{2}$ was computer-printed onto a piece of filter paper repeatedly, 40 times, and then the paper was cut into smaller pieces of $3.5 \times 1 \mathrm{~cm}^{2}$ for the visual detection of $\mathrm{F}^{-}$.

\section{Detection of $\mathbf{F}^{-}$in real samples using test paper}

Tap water, lake water, well water and human urine were chosen as the real water samples. Initially, the $\mathrm{F}^{-}$concentrations of real samples were determined by ion chromatography. Then 0, 9, 25, and $91 \mu \mathrm{M}$ standard $\mathrm{F}^{-}$solutions were spiked into samples. Further, samples spiked with $\mathrm{F}^{-}$were dropped onto the test 
paper and left for $20 \mathrm{~min}$. The fluorescent spectra of the test paper were recorded by a spectrometer at an excitation wavelength of $375 \mathrm{~nm}$, and fluorescence pictures were taken by a camera under a $365 \mathrm{~nm}$ UV lamp.

\section{Results and discussion}

\section{The synthesis and characterization of probe C-TIPS}

The non-fluorescent $\mathrm{F}^{-}$-sensitive probe was prepared according to the reported method. Here, 7-hydroxycoumarin was chosen as the initial mother fluorophore because of its simple structure and easy modification. A nucleophilic substitution reaction of commercially available 7-hydroxycoumarin with TIPS-Cl produced the compound C-TIPS in an appreciable yield $(89.7 \%)$ (Scheme 1). The chemical structure of C-TIPS was characterized by ${ }^{1} \mathrm{H}$ NMR, ${ }^{13} \mathrm{C}$ NMR and high-resolution mass spectrometry (HR-MS), as shown in Fig. S1-S3 (ESI†).

The fluorescence of the hydroxycoumarin moiety was quenched by covalently coupling with the TIPS group. ${ }^{41}$ Upon the addition of $\mathrm{F}^{-}$, the recovery of blue fluorescence from nonfluorescent C-TIPS clearly indicated that $\mathrm{F}^{-}$triggered the removal of the TIPS moiety from compound C-TIPS, producing the highly fluorescent hydroxycoumarin (Scheme 1). To confirm the fluorescent sensing mechanism, the reaction of C-TIPS with $\mathrm{F}^{-}$was monitored by HPLC and MS spectra. As shown in Fig. S5 (ESI $\dagger$ ), C-TIPS with a high purity only displayed a single peak at $11 \mathrm{~min}$ in HPLC spectra. After $1 \mathrm{mM} \mathrm{F}^{-}$was added into the solution of C-TIPS, it was clearly observed that the peak at $11 \mathrm{~min}$ disappeared and a new peak at $4 \mathrm{~min}$ was found in HPLC, indicating the reaction of C-TIPS with $\mathrm{F}^{-}$. For further identification of the final product of C-TIPS with $\mathrm{F}^{-}$, HR-MS spectra were investigated. The peak of C-TIPS at $\mathrm{m} / \mathrm{z}=$ 341.1540 was clearly observed (Fig. S3, ESI $\dagger$ ). After the reaction with $\mathrm{F}^{-}$, the peak of C-TIPS disappeared, and a new peak at $\mathrm{m} / \mathrm{z}$ $=161.0246$ was detected, which was identical to that of 7hydroxyl coumarin (Fig. S4, ESI $\dagger$ ). The above experimental results provide strong evidence that $\mathrm{F}^{-}$-induced the cleavage of the $\mathrm{Si}-\mathrm{O}$ bond.

\section{The construction of a ratiometric fluorescent system}

We employed red CdTe QDs as an internal standard to construct a ratiometric fluorescent system. Red CdTe QDs were ideal as they possess many excellent optical merits, including high extinction coefficients and high fluorescent quantum yields, together with other potential advantages: (1) inertness to $\mathrm{F}^{-}$

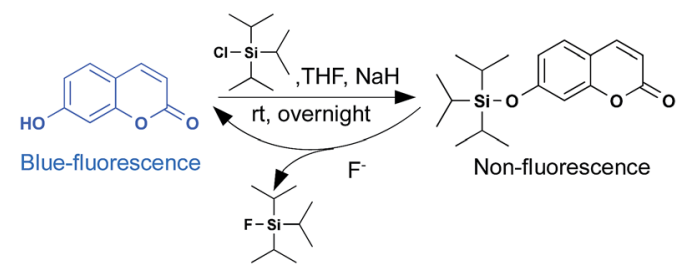

Scheme 1 The synthetic route of probe C-TIPS and the reaction mechanism of $\mathrm{C}$-TIPS with $\mathrm{F}^{-}$.
(Fig. S6, ESI $\dagger$ ), (2) assisting the mixing system to exhibit a wide color variation, (3) suitable excitation spectra, narrow emission peaks, and excellent photochemical stabilities. ${ }^{43}$ Significantly, the broad absorbance and excitation wavelength range of CdTe QDs covered the absorbance and excitation wavelength of 7hydroxycoumarin and C-TIPS (Fig. S7 and S8, ESI†), demonstrating that the ratiometric fluorescent solution could be excited by the same excitation source. The ratiometric fluorescent solution for the sensing of $\mathrm{F}^{-}$was obtained via the simple mixing of CdTe QDs and C-TIPS in an optimal ratio (Fig. 1A illustrates the detection mechanism). Upon the addition of increasing concentrations of $\mathrm{F}^{-}$, the ratiometric fluorescent solution exhibited a series of noticeable color alterations from the original red to ultimately blue, while the C-TIPS solution only gave a brightness change (Fig. 1B and C). Obviously, the color evolution was easier to discriminate with the naked eye than only the brightness change.

As is well known, the fluorescent ratio of blue/red plays a key role in tuning the emission color. If the ratio was not suitable, the intermediate color of red and blue would be shown as purple, greatly narrowing the color variation range. ${ }^{\mathbf{4 4 , 4 5}}$ Consequently, we studied systematically the relationship between the ratios and visual fluorescent color changes by adjusted the proportion of C-TIPS and CdTe QDs. As shown in Fig. S9 (ESI $\dagger$ ), it was found that when the fluorescent intensity ratio of red: blue was $1: 5$ or below, the fluorescent spectra of the mixture showed a wide spectral coverage in the visual range and a rich color alteration from the original red to ultimately blue (the inset of Fig. S9, ESI $\dagger$ ). Compared with the ratios of $1: 7,1: 10$ and $1: 15$, the ratio of $1: 5$ exhibited the richest color change

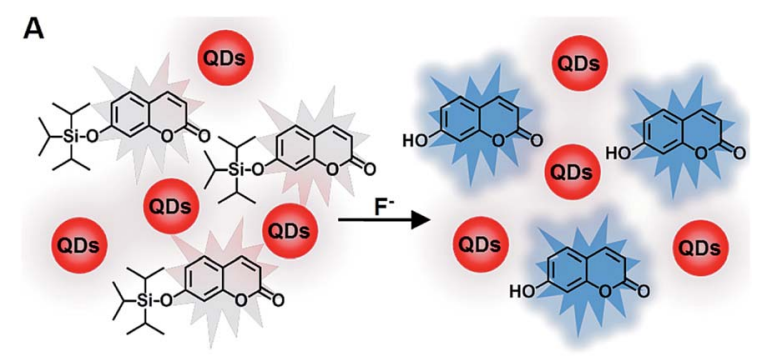

B

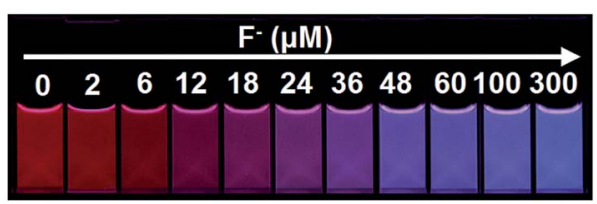

C

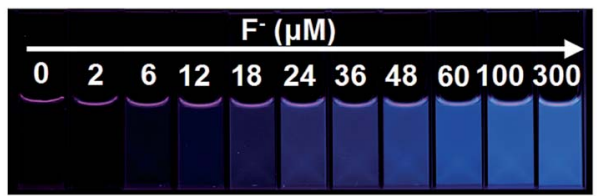

Fig. 1 (A) The ratiometric fluorescent sensing mechanism of the mixture of C-TIPS/CdTe QDs to $\mathrm{F}^{-}$. The visual effects of (B) the mixture of C-TIPS/CdTe QDs, (C) only C-TIPS, in $\mathrm{EtOH} / \mathrm{H}_{2} \mathrm{O}(7: 3, \mathrm{v} / \mathrm{v})$ after the addition of different concentrations of $\mathrm{F}^{-}$for $20 \mathrm{~min}$. The corresponding photos were taken under a $365 \mathrm{~nm}$ UV lamp. 
from red to peach to purple and to the final blue. Thus, the fluorescent intensity ratio of the $1: 5 \mathrm{red} / \mathrm{blue}$ was selected as the optimal ratio in the following experiments. The solvent system for the fluorescence detection of $\mathrm{F}^{-}$was optimized, and $7: 3 \mathrm{EtOH} / \mathrm{H}_{2} \mathrm{O}$ proved to be the ideal solvent in the detection system (Fig. S10, ESI $\dagger$ ).

\section{The detection of $\mathrm{F}^{-}$with the mixture solution of C-TIPS/CdTe QDs}

A fluorescent titration experiment was performed to evaluate the sensitivity of the mixture solution of C-TIPS/CdTe QDs to $\mathrm{F}^{-}$, and the corresponding fluorescent spectra were recorded by a fluorescence spectrophotometer. As shown in Fig. 2A, along with increasing the concentration of $\mathrm{F}^{-}$, the fluorescence intensity at $455 \mathrm{~nm}\left(I_{455}\right)$ increased gradually, and the fluorescence intensity at $630 \mathrm{~nm}\left(I_{630}\right)$ kept very steady. The variation of the intensity ratios of the two emission peaks $\left(I_{455} / I_{630}\right)$ resulted in a distinguishable fluorescent color change from red to purple and to blue, which is available for the visual quantification of $\mathrm{F}^{-}$. As shown in Fig. $2 \mathrm{~B}$, the fluorescence intensity ratio $\left(I_{455} / I_{630}\right)$ was closely related to the dosage of $\mathrm{F}^{-}$and displayed a good linearity

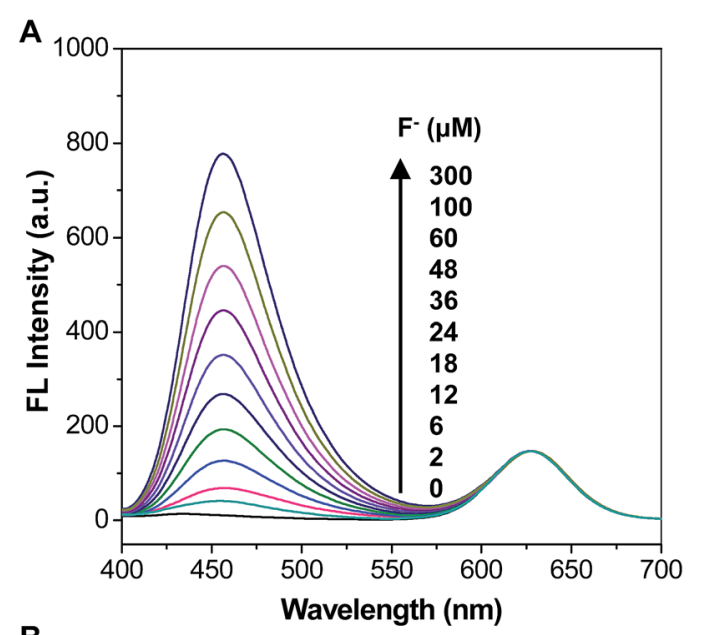

B

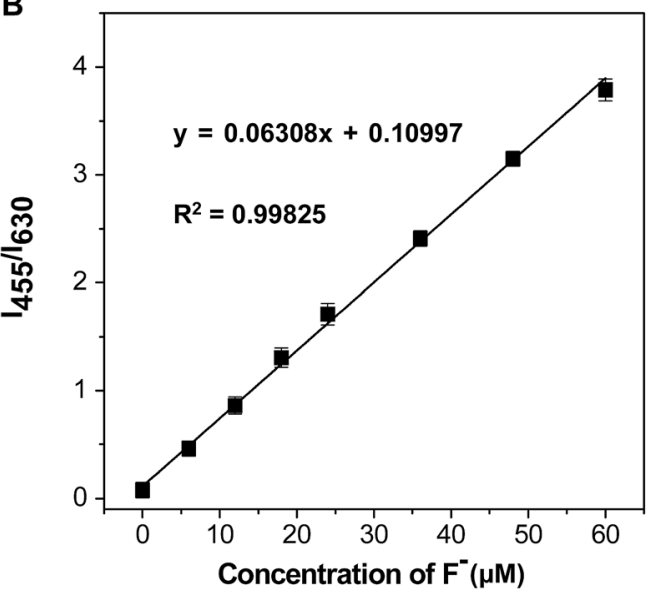

Fig. 2 (A) Fluorescence spectra of the mixture of C-TIPS/CdTe QDs in $\mathrm{EtOH} / \mathrm{H}_{2} \mathrm{O}(7: 3, \mathrm{v} / \mathrm{v})$ after the addition of different concentrations of $\mathrm{F}^{-}$for $20 \mathrm{~min}\left(\lambda_{\mathrm{ex}}=375 \mathrm{~nm}\right)$. (B) Plots of fluorescence ratios $I_{455} / I_{630}$ versus $\mathrm{F}^{-}$concentrations. with the $\mathrm{F}^{-}$concentrations in the range of 0 to $60 \mu \mathrm{M}$, with standard deviation $R^{2}=0.99825$. The detection limit $(3 \sigma)$ was calculated to be $0.285 \mu \mathrm{M}$. Compared with the detection limit of previously reported $\mathrm{Si}-\mathrm{O}$ bond-breaking probes (Table S1, ESI $\dagger$ ), our strategy has a comparatively lower detection limit, which is lower than the WHO defined limit $(79 \mu \mathrm{M})$ in drinking water. The results indicated that the mixing system of C-TIPS/CdTe QDS could actually satisfy the requirements for the trace analysis of $\mathrm{F}^{-}$.

\section{The selectivity to $\mathrm{F}^{-}$of the mixing solution of C-TIPS/CdTe QDs}

It was worth mentioning that there were a large number of anions in the environmental water, potentially causing interference in the detection of $\mathrm{F}^{-}$. Therefore, it was very significant to test the selectivity of the mixing system of C-TIPS/CdTe QDs towards $\mathrm{F}^{-}$ by monitoring the response of the fluorescence intensity $\left(I_{455}\right)$ $\left.I_{630}\right)$ to these anions. Fig. 3 shows that $\mathrm{F}^{-}$at $300 \mu \mathrm{M}$ induced a significant enhancement of the emission ratio of $I_{455} / I_{630}$ by about 55-fold, whereas $300 \mu \mathrm{M} \mathrm{Cl}^{-}, \mathrm{Br}^{-}, \mathrm{I}^{-}, \mathrm{ClO}_{4}{ }^{-}, \mathrm{HCO}_{3}{ }^{-}, \mathrm{NO}_{2}{ }^{-}$, $\mathrm{H}_{2} \mathrm{PO}_{4}{ }^{-}, \mathrm{AcO}^{-}, \mathrm{NO}_{3}{ }^{-}$and $\mathrm{SCN}^{-}$did not cause any obvious fluorescence response, demonstrating that the mixing system displayed a high specificity to $\mathrm{F}^{-}$. In addition, the dynamics experiments indicated that the reaction of C-TIPS with $\mathrm{F}^{-}$was completed in 15 min (Fig. S11, ESI $\dagger$ ). The above results suggested that the sensory system could be used for the quantification of $\mathrm{F}^{-}$ with high selectivity, outstanding sensitivity, and fast dynamics.

To further examine the practical reliability of the sensory system, we applied it to sensing $\mathrm{F}^{-}$levels in samples such as tap water, lake water, well water, and human urine. First, the natural amounts of $\mathrm{F}^{-}$in lake water, tap water, well water, and human urine were 9.3 $\mu \mathrm{M}, 9.1 \mu \mathrm{M}, 9.0 \mu \mathrm{M}$, and $8.9 \mu \mathrm{M}$, measured by ion chromatography, respectively. Then known amounts of $\mathrm{F}^{-}$were spiked into samples. The eventual amounts of $\mathrm{F}^{-}$in the samples were measured according to the excellent linear relationship shown in Fig. 2B. Table 1 and $\mathrm{S} 2 \uparrow$ show that the sensory system worked quite well in lake water, tap water, well water, and human urine, with a recovery of more than $96.5 \%$, indicating the potential application of the sensory system for the analysis of $\mathrm{F}^{-}$in real samples.

\section{The preparation of a paper sensor and detection of $\mathrm{F}^{-}$in real samples}

To endow the mixing system with simple and portable features, we further developed fluorescent test paper for the visual quantification of $\mathrm{F}^{-}$to verify its dosage-sensitive ability. The mixture of C-TIPS/CdTe QDs as ink was inkjet-printed onto a piece of filter paper by operating a computer (the visual guide is show in Fig. 4A). The filter papers without any background fluorescence could effectively avoid disturbance to the detection results. The C-TIPS/CdTe QDs mixture ink was evenly adhered to the surface of filter papers by printing repeatedly 40 times, and the as-prepared test paper emitted red fluorescence under the $365 \mathrm{~nm}$ UV lamp. Importantly, the test paper remained stable after being stored in a $4{ }^{\circ} \mathrm{C}$ refrigerator for 30 days (Fig. S12, ESI $\dagger$ ). When the aqueous solution of $\mathrm{F}^{-}$was added and infiltrated into the surface of test papers, dramatic color 

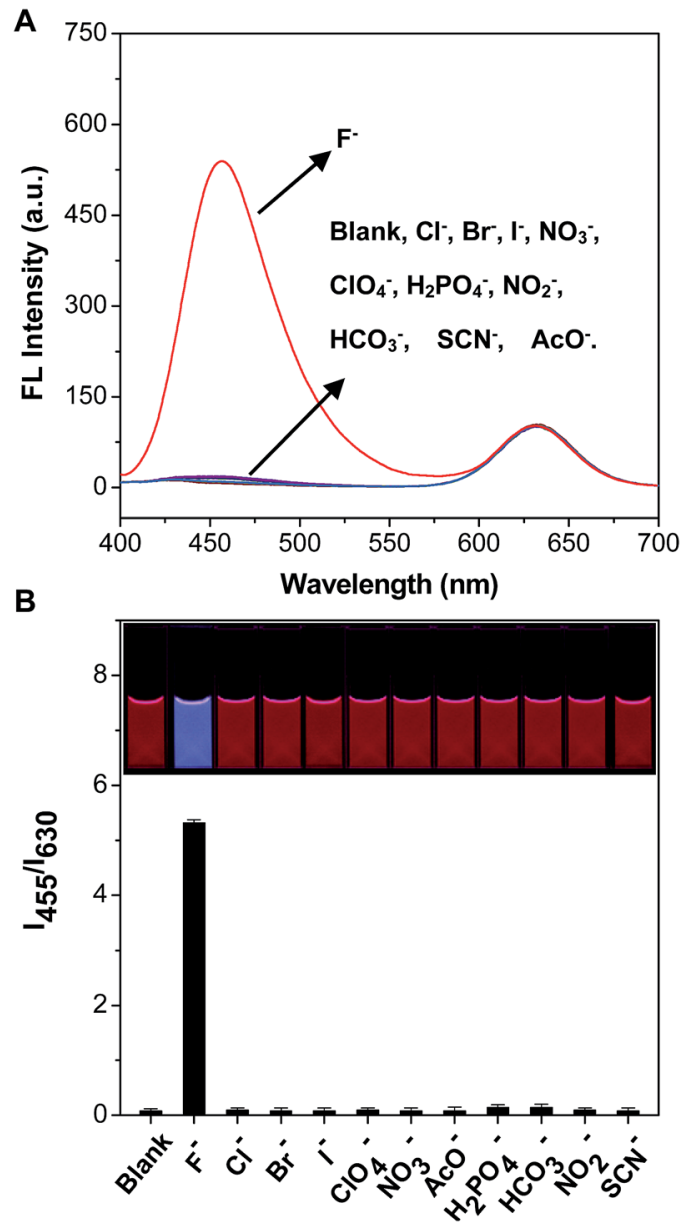

Fig. 3 The selective fluorescence responses of the mixture of $\mathrm{C}$-TIPS/ $\mathrm{CdTe} Q \mathrm{QDs}$ in $\mathrm{EtOH} / \mathrm{H}_{2} \mathrm{O}(7: 3, \mathrm{v} / \mathrm{v})$ with the addition of various anions at $300 \mu \mathrm{M}\left(\mathrm{F}^{-}, \mathrm{Cl}^{-}, \mathrm{Br}^{-}, \mathrm{I}^{-}, \mathrm{ClO}_{4}{ }^{-}, \mathrm{HCO}_{3}{ }^{-}, \mathrm{NO}_{2}{ }^{-}, \mathrm{H}_{2} \mathrm{PO}_{4}{ }^{-}, \mathrm{AcO}^{-}, \mathrm{NO}_{3}{ }^{-}\right.$ and $\mathrm{SCN}^{-}$) for $20 \mathrm{~min}$. (A) The fluorescence spectra $\left(\lambda_{\mathrm{ex}}=375 \mathrm{~nm}\right)$. (B) The column chart. The inset shows the corresponding photos under a $365 \mathrm{~nm}$ UV lamp.

changes were observed under a UV lamp. As shown in Fig. 4B, each dosage $(0,2,6,12,18,24,36,48,60,100,300 \mu \mathrm{M})$ induced eye-distinguishable color evolutions from the original red to peach to pink to purple to final blue, consistent with our experimental results in solution.

Furthermore, to verify the dosage-sensitive efficacy and accuracy of test paper for the visual quantification of $\mathrm{F}^{-}$in environmental waters, the test paper was applied to detecting $\mathrm{F}^{-}$in

Table 1 The recoveries of $\mathrm{F}^{-}$spiked in local lake water and tap water using the C-TIPS/CdTe mixture system

\begin{tabular}{llllll}
\hline & \multicolumn{2}{l}{ Lake water } & & Tap water & \\
\cline { 2 - 3 } $\begin{array}{l}\text { Spiked } \mathrm{F}^{-} \\
(\mu \mathrm{M})\end{array}$ & $\begin{array}{l}\text { Found } \\
(\mu \mathrm{M})\end{array}$ & $\begin{array}{l}\text { Recovery } \\
(\%)\end{array}$ & & $\begin{array}{l}\text { Found } \\
(\mu \mathrm{M})\end{array}$ & $\begin{array}{l}\text { Recovery } \\
(\%)\end{array}$ \\
\hline 0 & 9.7 & $104.3 \pm 3.8$ & 9.4 & $103.3 \pm 4.3$ \\
12 & 21.6 & $101.4 \pm 2.9$ & 21.5 & $101.9 \pm 3.7$ \\
36 & 46.1 & $101.8 \pm 4.1$ & & 46.3 & $102.7 \pm 3.3$ \\
100 & 111.2 & $101.7 \pm 3.7$ & & 111.5 & $102.2 \pm 3.6$
\end{tabular}

A

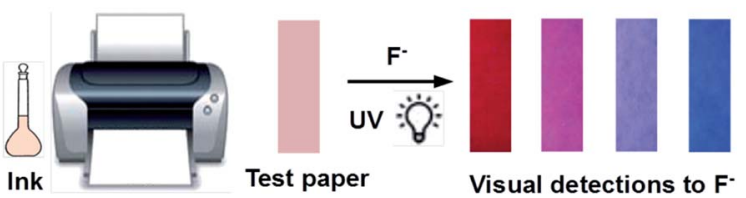

B

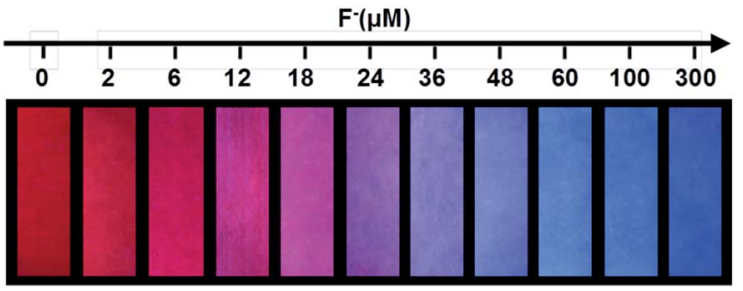

C

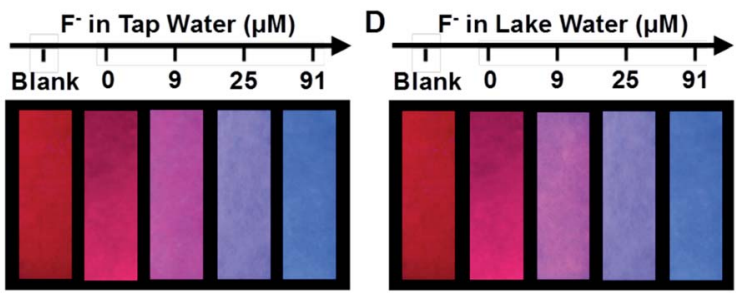

Fig. 4 (A) Visual guide to the preparation of the test papers by printing C-TIPS/CdTe QDs ink onto a piece of filter paper. (B) Visualization of $\mathrm{F}^{-}$using the fluorescent test papers. (C, D) Visual detections of $\mathrm{F}^{-}$in tap water and lake water, respectively. The photos were taken under a $365 \mathrm{~nm}$ UV lamp.

samples such as tap water, lake water, well water, and human urine. When the natural $\mathrm{F}^{-}$amounts in samples $(\sim 9 \mu \mathrm{M})$ were detected by the as-prepared test paper, the visual outcome conformed to the color standard between $6 \mu \mathrm{M}$ and $12 \mu \mathrm{M}$, as shown in Fig. 4B. In addition, we spiked $\mathrm{F}^{-}$at 9, 27, and $91 \mu \mathrm{M}$ into samples, and the detected concentrations of the $\mathrm{F}^{-}$were in good agreement with the colors exhibited at the 18,36 , and $100 \mu \mathrm{M}$ concentrations of $\mathrm{F}^{-}$as shown in Fig. 4B (Fig. 4C, D and S13, $\mathrm{ESI} \dagger$ ). The corresponding fluorescence spectra of test papers are shown in Fig. S14 (ESI $\dagger$ ). The detection results further confirmed that the fluorescent test papers could actually be applied to the visual detection of $\mathrm{F}^{-}$in environmental water samples.

\section{Conclusions}

In summary, we have prepared a ratiometric fluorescent test paper with high sensitivity and selectivity for the visual and onsite quantification of $\mathrm{F}^{-}$. The ratiometric fluorescent system was composed of the $\mathrm{F}^{-}$-sensitive organic probe and $\mathrm{F}^{-}$-inert red CdTe QDs. Upon the addition of $\mathrm{F}^{-}$, the blue fluorescence of the organic probe could be lit up, while the red fluorescence of CdTe QDs stayed unchanged, and consequently the test paper exhibited a consecutive color evolution from the original red to the final blue, with the lowest discernible dosage as low as $6 \mu \mathrm{M}$ by observation with the naked eye. Importantly, the fluorescent test papers have successfully been used for the visual assays of $\mathrm{F}^{-}$in environmental waters. The strategy researched herein proposes a promising method of ratiometric fluorescent test papers for the determination of $\mathrm{F}^{-}$and can also be extensively 
applied to the visual and on-site assays of multitudinous analytes in environments, medicines, and foods.

\section{Conflicts of interest}

There are no conflicts to declare.

\section{Acknowledgements}

This work is supported by the National Natural Science Foundation of China (Grants 21335006, 21475135, 21375131, 21371174, and 21703255), National Basic Research Program of China (Grant 2015CB932002), China-Singapore Joint Project (Grant 2015DFG92510), Science and Technology Service Network Initiative of the Chinese Academy of China (Grant KFJSW-STS-172) and the Natural Science Foundation of Anhui Province (Grant 1608085QB32, Grant 1708085MB35).

\section{Notes and references}

1 Y. Zhou, J. F. Zhang and J. Yoon, Chem. Rev., 2014, 114, 55115571.

2 L. Gai, J. Mack, H. Lu, T. Nyokong, Z. Li, N. Kobayashi and Z. Shen, Coord. Chem. Rev., 2015, 285, 24-51.

3 World Health Organization, Guidelines for drinking water quality, World Health Organization, 3rd edn incorporating, 1st and 2nd addenda, Geneva, 2008.

4 P. Singh, M. Barjatiya, S. Dhing, R. Bhatnagar, S. Kothari and V. Dhar, Urol. Res., 2001, 29, 238-244.

5 E. B. Bassin, D. Wypij, R. B. Davis and M. A. Mittleman, Cancer, Causes Control, Pap. Symp., 2006, 17, 421-428.

6 S. Ayoob and A. K. Gupta, Crit. Rev. Environ. Sci. Technol., 2006, 36, 433-487.

7 D. A. P. Tanaka, S. Kerketta, M. A. L. Tanco, T. Yokoyama and T. M. Suzuki, Sep. Sci. Technol., 2002, 37, 877-894.

8 R. De Marco, G. Clarke and B. Pejcic, Electroanalysis, 2007, 19, 1987-2001.

9 H. Yiping and W. Caiyun, Anal. Chim. Acta, 2010, 661, 161166.

10 Z. Liu, K. Ren, Y. Chen, Y. Li, J. Xie, Y. Ding, L. Li, K. Li, W. Zhu, W. Yang and Z. Xu, RSC Adv., 2017, 7, 38160-38165.

11 S. Shweta, A. Kumar, N. Neeraj, S. K. Asthana and K. K. Upadhyay, New J. Chem., 2017, 41, 5098-5104.

12 L. Ma, N. Sun, C. Tu, Q. Zhang and A. Diao, RSC Adv., 2017, 7, 38512-38518.

13 K. Du, S. Niu, L. Qiao, Y. Dou, Q. Zhu, X. Chen and P. Zhang, RSC Adv., 2017, 7, 40615-40620.

14 E. J. Cho, J. W. Moon, S. W. Ko, J. Y. Lee, S. K. Kim, J. Yoon and K. C. Nam, J. Am. Chem. Soc., 2003, 125, 12376-12377.

15 D. Sharma, S. K. Sahoo, S. Chaudhary, R. K. Bera and J. F. Callan, Analyst, 2013, 138, 3646.

16 G. Jiang, X. Liu, Y. Wu, J. Wang, X. Dong, G. Zhang, Y. Li and X. Fan, RSC Adv., 2016, 6, 59400.

17 X. Liu, D. Bai and S. Wang, Angew. Chem., 2006, 118, 56015604.

18 Q. Zhang, Q. Qu, S. Chen, X. Liu and P. Li, Food Chem., 2017, 231, 295-300.
19 L. Li, Y. Ji and X. Tang, Anal. Chem., 2014, 86, 10006-10009. 20 P. Hou, S. Chen, H. Wang, J. Wang, K. Voitchovsky and X. Song, Chem. Commun., 2014, 50, 320-322.

21 B. Ke, W. Chen, N. Ni, Y. Cheng, C. Dai, H. Dinh and B. Wang, Chem. Commun., 2013, 49, 2494-2496.

22 R. Suresh, S. K. Thiyagaraj and P. Ramamurthy, Phys. Chem. Chem. Phys., 2016, 18, 32247-32255.

23 B. Qiu, Y. Zeng, L. Cao, R. Hu, X. Zhang, T. Yu, J. Chen, G. Yang and Y. Li, RSC Adv., 2016, 6, 49158-49163.

24 B. Zhu, F. Yuan, R. Li, Y. Li, Q. Wei, Z. Ma, B. Du and X. Zhang, Chem. Commun., 2011, 47, 7098-7100.

25 N. Kumari, N. Dey and S. Bhattacharya, Analyst, 2014, 139, 2370-2378.

26 X. Zhou, R. Lai, H. Li and C. I. Stains, Anal. Chem., 2015, 87, 4081-4086.

27 M. Yoo, S. Park and H.-J. Kim, $R S C A d v .$, 2016, 6, 1991019915.

28 Y. Bao, B. Liu, H. Wang, J. Tian and R. Bai, Chem. Commun., 2011, 47, 3957-3959.

29 Y. Li, Y. Duan, J. Zheng, J. Li, W. Zhao, S. Yang and R. Yang, Anal. Chem., 2013, 85, 11456-11463.

30 S. Goswami, A. K. Das, A. Manna, A. K. Maity, H.-K. Fun, C. K. Quah and P. Saha, Tetrahedron Lett., 2014, 55, 2633-2638.

31 Z. Chen, Y. Niu, G. Cheng, L. Tong, G. Zhang, F. Cai, T. Chen, B. Liu and B. Tang, Analyst, 2017, 142, 2781-2785.

32 X. Chen, N. Zheng, S. Chen and Q. Ma, Anal. Methods, 2017, 9, 2246-2251.

33 K. Zhang, H. Zhou, Q. Mei, S. Wang, G. Guan, R. Liu, J. Zhang and Z. Zhang, J. Am. Chem. Soc., 2011, 133, 8424-8427.

34 Q. Mei and Z. Zhang, Angew. Chem., Int. Ed., 2012, 51, 56025606.

35 P. Nath, R. K. Arun and N. Chanda, RSC Adv., 2015, 5, 6902469031.

36 X. Liu, W. Zhang, C. Li, W. Zhou, Z. Li, M. Yu and L. Wei, RSC Adv., 2015, 5, 4941-4946.

37 Q. Mei, H. Jing, Y. Li, W. Yisibashaer, J. Chen, B. Li and Y. Zhang, Biosens. Bioelectron., 2016, 75, 427-432.

38 R. Zhang, J. Zhao, G. Han, Z. Liu, C. Liu, C. Zhang, B. Liu, C. Jiang, R. Liu, T. Zhao, M. Han and Z. Zhang, J. Am. Chem. Soc., 2016, 138, 3769-3778.

39 M. Lan, J. Zhang, Y.-S. Chui, P. Wang, X. Chen, C.-S. Lee, H.-L. Kwong and W. Zhang, ACS Appl. Mater. Interfaces, 2014, 6, 21270-21278.

40 Y. Zhou, X. Huang, C. Liu, R. Zhang, X. Gu, G. Guan, C. Jiang, L. Zhang, S. Du, B. Liu, M. Y. Han and Z. Zhang, Anal. Chem., 2016, 88, 6105-6109.

41 P. Sokkalingam and C.-H. Lee, J. Org. Chem., 2011, 76, 38203828.

42 Y. Wang, C. Zhang, X. Chen, B. Yang, L. Yang, C. Jiang and Z. Zhang, Nanoscale, 2016, 8, 5977-5984.

43 C. Xie, L. Xiao, S. Peng and X. Shi, New J. Chem., 2014, 38, 6095-6102.

44 X. Huang, Y. Zhou, C. Liu, R. Zhang, L. Zhang, S. Du, B. Liu, M. Han and Z. Zhang, Biosens. Bioelectron., 2016, 86, 530-535. 45 C. Liu, D. Ning, C. Zhang, Z. Liu, R. Zhang, J. Zhao, T. Zhao, B. Liu and Z. Zhang, ACS Appl. Mater. Interfaces, 2017, 9, 18897-18903. 